\title{
ENGINEERING METHODOLOGY FOR ORGANISATION NETWORKS
}

\author{
X.Boucher', A.Zaidat ${ }^{2}$, L.Vincent ${ }^{1}$ \\ 1-Clermond-Ferrand 1 University,Technology Institute, ali.zaidat@iut.u-clermont1.fr \\ 2-Ecole nationale supérieure des mines de Saint Etienne, G2I, \{boucher, vincent\}@emse.fr \\ FRANCE
}

\begin{abstract}
This paper presents the key features of an engineering methodologv dedicated to Organisation Networks. This methodology constitutes one of the elements of a full engineering framework developed through a PhD research thesis. The authors mainly focus hereafter on specifying the "design" and "preliminary" engineering" activities of the engineering procedure. The methodology is illustrated on a case study' from the sector of metallurgical industry.
\end{abstract}

\section{INTRODUCTION}

This paper reports some elements of a $\mathrm{PhD}$ research focusing on a modelling architecture and engineering methodology dedicated to a specific cooperative structure: "organisation networks" (Zaidat, 2005). The basic hypothesis and specificities concerning organisation networks, as well as the modeling architecture have been previously published in (Zaidat et al., 2005) (Zaidat et al., 2006).

The objective of an engineering methodology is to specify the procedure required for an engineering objective and to provide the tools (mainly models) necessary for the engineering activities. An engineering methodology can be modelled by a set of activity diagrams or procedures with a detailed description of the various engineering activity tasks. Our proposal for Organisation Networks is based on methodologies from information system engineering (Merise, object oriented methods and methods for open distributed systems), enterprise engineering (IDEF, CIMOSA, PERA, GRAI-GIM, and Zachman methodology), and cooperative structure engineering (Zwegers et al., 2003), (Teleflow, 1998), (Chalmetta, 2003). The engineering framework presented hereafter mainly comes from a specialisation of the two reference frameworks: [GERAM 2000] and VERAM [Zwegers et al. 2003], with the objective to provide a full implementation of GERAM. Indeed, GERAM provides a well-established generic framework, but nearly no complete implementation on any specific area can be found in the literature.

Organisation networks constitute a breeding environment with a long term life cycle [Zwegers et al. 2003], from which partners develop specific "businesses" which represent short term cooperation structures. Thus, this study will refer to two main enterprise modelling entities: "Organisation Network" (ON.) and "Business". For each enterprise entity, an engineering life-cycle and a modelling framework have been specified.

Concerning the life-cycle of enterprise entities, we will refer below to the first four phases defined in the methodology (Zaidat, 2005): (1) Organisation

Boucher, X., Zaidat, A., Vincent, L., 2007, in IFIP International Federation for Information Processing, Volume 243, Establishing the Foundation of Collaborative Networks; eds. Camarinha-Matos, L., Afsarmancsh, H., Novais, P., Analide, C.; (Boston: Springer), pp. 639-648. 
Network/Business identification; (2) Organisation Network/Business definition; (3) Design; (4) Preliminary engineering.

Concerning the modelling framework, four modelling views have been specified in (Zaidat et al., 2006). First, to represent the functioning mechanisms, the organisational structure, the resources and flows of a breeding environment or specific business we defined two "content views" called the "functional view" and the "organisational view". In addition, two independent modeling views dealing with the integration issues in the organisation network engineering have been defined: the "application view" and the "knowledge view".

The objective of this communication is to focus on the engineering methodology by presenting some key features of engineering activities specified to build both Organisation Networks and specific Businesses. Section 2 introduces the case study used to illustrate the methodology, and section 3 specifies the engineering activities, putting the focus on the "design" and "preliminary engineering" life-cycle phases.

\section{CASE STUDY}

The methodology was tested on a case study built from real experiences. The case study "PYRAMICA" presented below, is based on the creation and the operation of two real SME networks working in the sector of metallurgical industry and studied during the GrecoPME project (Grecopme project, 2003).

The creation of the network PYRAMICA has been initiated by two SMEs SURFPAINT (enterprise specialised in painting and surface treatment) and METAGRIT (enterprise specialised in gritting and metal deposits). In a regional context of externalisation from the main contractors, the two SMEs have chosen a strategic vision of collaboration on the market, based on complementary services. Their strategy consists in offering integrated products based on both mechanical and electrical components. They defined four business types in the domain of integrated mechanical and electrical products: (1) Switchgear cubicle; (2) Safety devices for the national markets; (3) Safety devices for the international market and (4) Safety hoods.

SURFPAINT and METAGRIT have decided to develop a vertical cooperation to carry out these businesses. This means first to proceed to the selection of partners in order to get complementary macro-competencies. The selection process led them to choose the three following partners (who gave their agreement to take part in PYRAMICA operations).

- ROUANESHEET-METAL with macro-competencies in sheetmetal treatment;

- MACHWIR with macro-competencies in machine assembly and wiring;

- CPELEC specialised in manufacturing of electrical engineering sub-sets.

The partners have proceeded to some of the most difficult activities of the Organisation Network Engineering Methodology, which consists in applying to PYRAMICA the design and preliminary engineering phases. In this paper, we will describe the application of our methodology on the business "Production and Delivery of Safety Devices for the International Markets" (PDSDIM). This process is described in annexe 1.1. The case study will mainly illustrate the application of the engineering procedure for the design and preliminary engineering.

Our engineering framework has been implemented on the enterprise modelling toolkit ADONIS developed by the Austrian company BOC. The power of Adonis is 
linked to its strong adaptability provided by a meta-modeling approach. This approach offers the opportunity to develop specific modelling libraries. Adonis also proposes different programming languages - e.g. in order to implement evaluation and simulation methods-.

\section{ENGINEERING METHODOLOGY}

Engineering activities are distributed among the main engineering phases specified in the Life-Cycle of our modeling framework: Network identification, Network definition, Design and Preliminary engineering. We do not detail hereafter the network identification and definition phases, which are mainly based on the re-use of the TELEfow project results (1998). We specify below the design and preliminary engineering phases.

To support engineering tasks, the methodology uses a large set of models, with the objective to build a full specification of the four modeling views introduced before: Functional, Organisational, Application and Knowledge views. The figure below provides an overview of all the models required, for each modeling view. We illustrate hereafter the progressive building of these models, throughout the engineering procedure (for "Design" and "Preliminary Engineering" steps).

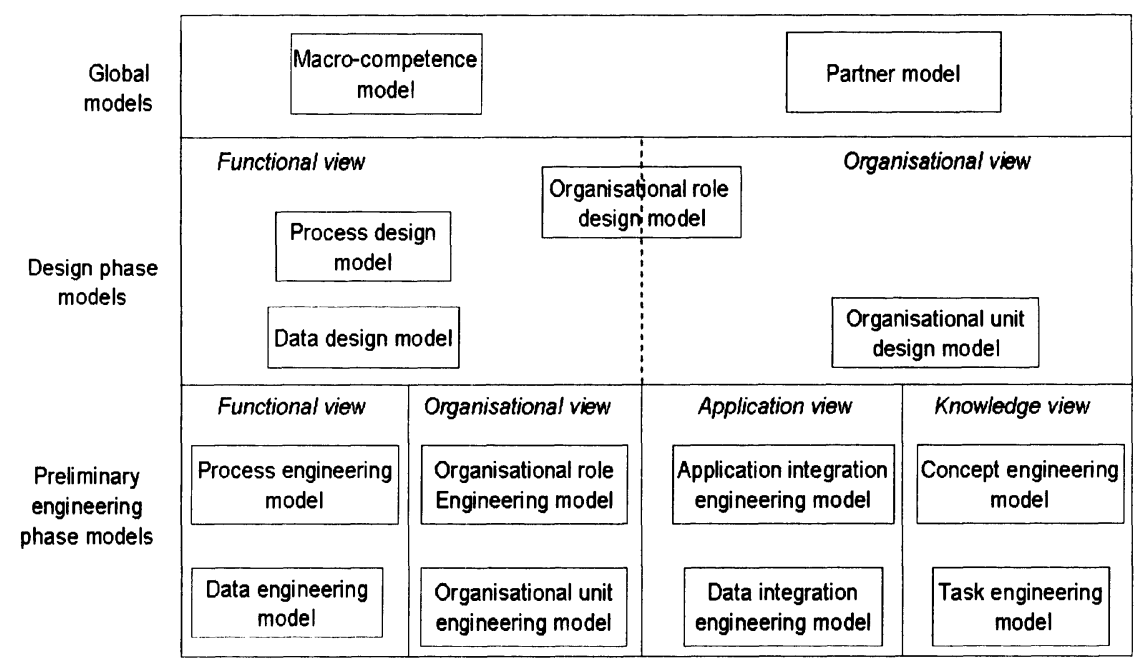

Figure 1 - Engineering Models

\subsection{Design}

The design phase provides design solutions for the future functioning and organisational structures of the $\mathrm{ON}$ and of the different businesses. Figure 2 presents the engineering activities associated with the design phase (detailed below). 


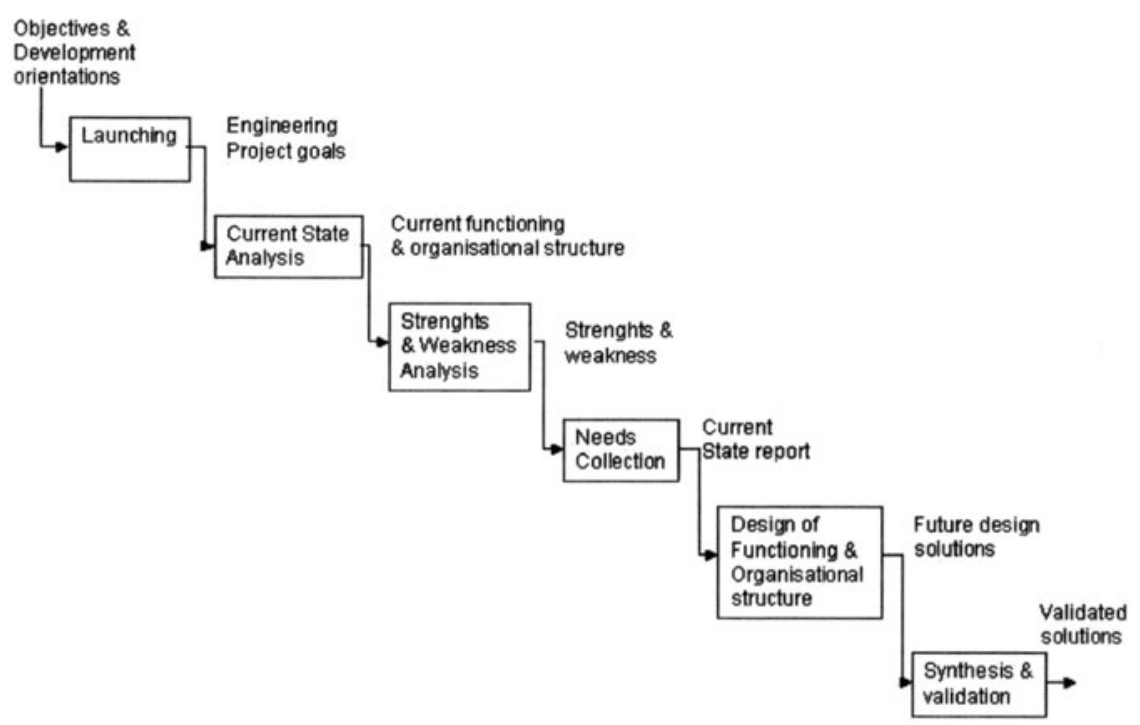

Figure 2 - Engineering activities for the design phase

The goal of the design phase is to define the organisational levels and to give an overall description of the functioning and organisational structures for each decomposed organisational unit. During these engineering activities, the four design models of figure 1 are built (by the tasks described in table1) and they will be later detailed during the preliminary engineering by providing organisational solutions.

Considering that the PYRAMICA Network is under creation, the activities "Current state analysis" and "strengths \&weaknesses analysis" are not applied (we just explain them conceptually, without case study application). After "launching" and "needs collection", we are mainly interested by illustrating the results of the "design" activity.

Launching: This activity defines the objectives and development policies related to the organisation network and the specific businesses. Launching increases team projects awareness on the objectives and the importance of the design and preliminary engineering phases. Finally this activity triggers the set up of the $\mathrm{ON}$.

Current state analysis: This analysis concentrates on understanding the current functioning and organisational structures, application integration solutions, concept models, and task models of the ON and of the different businesses. All the modelling views are necessary for the current state analysis, as shown in Table 1.

Strengths and weaknesses analysis: the results of the previous activity are used in order to analyse strength/weaknesses and to collect information relevant to user needs as well as criticism. The analysis of strengths and weaknesses consists in describing the strong points and the weak points related to the Organisation Network global operation. This is an analysis of current state of the ON, the different businesses, and the relationships between them. 
Needs collection: The goal of this activity is to collect development needs related to the Organisation Network, the different businesses, and their relationships. This brings the actors to publish a "current state report" gathering the results of analyses related to both enterprise entities ("Organisation Network" and "Business"). The current state is analysed in terms of operation, organisational structure, partner participation, etc. This report is the starting point for the next activity of design solution building.

In the case of PYRAMICA, the partners have come up with a considerable set of needs regarding the functioning and organisational structures of the PDSDIM business. Examples of the most general needs:

The partners will take part in the business operation according to their macrocompetencies.

- Each organisational unit has to be specialised on a set of specific missions.

- The authority and the responsibility must be clearly specified for each business.

- The partners will grant data access to technical information from their partners.

Etc...

Table 1 - Engineering tasks for current state analysis

\begin{tabular}{|l|l|}
\hline Modelling View & \multicolumn{1}{|c|}{ Engineering tasks } \\
\hline Functional view & $\begin{array}{l}\text { Modelling of the organisational roles } \\
\text { Modelling of the inter-organisational role processes by describing sub- } \\
\text { processes and activitics defincd in these rolcs. } \\
\text { Modelling of the object vicws and their relationships. } \\
\text { Description of integration solutions related to logistic, culture, ctc. These } \\
\text { solutions arc developed at the process level and they are not taken into account } \\
\text { in the integration vicws. }\end{array}$ \\
\hline $\begin{array}{l}\text { Organisational } \\
\text { view }\end{array}$ & $\begin{array}{l}\text { Modelling of the organisational units, organisational roles, and their } \\
\text { relationships. } \\
\text { Modelling of resources } \\
\text { Modelling of partner participation }\end{array}$ \\
\hline Application view & $\begin{array}{l}\text { Modelling of the current applications used, their relationships, messages } \\
\text { cxchanged, and synchronisation actions carricd out. }\end{array}$ \\
\hline Knowledge view & $\begin{array}{l}\text { Description of concept models } \\
\text { Description of task models }\end{array}$ \\
\hline
\end{tabular}

Design of functioning and organisational structures: at this stage, the specification of the future design solutions is only applied to the content views. Integration solutions will be studied in preliminary engineering, after the processes design activity. Referring to the overall orientations stated in the definition phase, this activity uses the "current state report" to build future design solutions, describing the functioning and organisational structures of the "Organisation Network" and "Businesses". This activity validates the objectives and puts priorities on goals, strong points, weak points and collected needs. The main engineering tasks are listed below. Referring to the modelling approach principles these tasks are applied to each organisational unit and at all the abstraction levels. 
Table 2 - Engineering tasks for functional and organisational design

\begin{tabular}{|l|l|}
\hline Modelling View & \multicolumn{1}{c|}{ Engineering tasks } \\
\hline Functional view & $\begin{array}{l}\text { Design of organisational roles by assigning their missions and objectives } \\
\text { Design of inter-organisational processes } \\
\text { Design of data models. }\end{array}$ \\
\hline $\begin{array}{l}\text { Organisational } \\
\text { view }\end{array}$ & $\begin{array}{l}\text { Design of the organisational units by specifying their missions and objectives } \\
\text { Allocation of the organisational roles to the organisational units } \\
\text { Overall definition of partner participations to these units }\end{array}$ \\
\hline
\end{tabular}

The application of the design activity to PYRAMICA Network has resulted in several operational models defined in ADONIS modeling environment. Six organisational roles have been specified. Referring to the construct of "organisational role" defined in the methodology (Zaidat et al., 2005), such roles are characterised by the attributes "missions", "rights/obligation" and "performance indicators". In case we refer to decision roles, we add decisional attributes "decision horizon", "decision period". The PDSDIM process of PYRAMYCA Network requires the roles "Business coordinator", "Assembler", "Sheet-metal worker", "Safety mechanism maker", "Surface processor", "Painter". These organisational roles required for the business processes will be taken in charge by five organisational units available among the network members. These organisational units are specified in the organisational view.

The functional view has also led to define inter-organisational processes and a data model. An example of process presented in annexel.1 describes how organisational units of the PDSDIM cooperate to make and deliver safety devices to the international markets based on the organisational roles introduced above.

Synthesis and validation: the design solutions proposed by the project team are validated by a strategic committee, whose decisions are based on several inputs: current state report; list of priorities on objectives, strong points, weak points, criticisms, and needs; list of design solutions describing the future operation and organisational structure of the $\mathrm{ON}$ and of the different businesses. In collaboration with the project team, the strategic committee confirms the development policies of the "Organisation Network" and "Businesses", and validates the design solutions.

\subsection{Preliminary engineering}

The preliminary engineering step deeper evaluates the potential implementation of a network or a single business, in order to make it possible to compare and/or simulate these solutions. The purpose is to specify the "How" the network should be implemented. Figure 3 presents the engineering activities of this phase. 


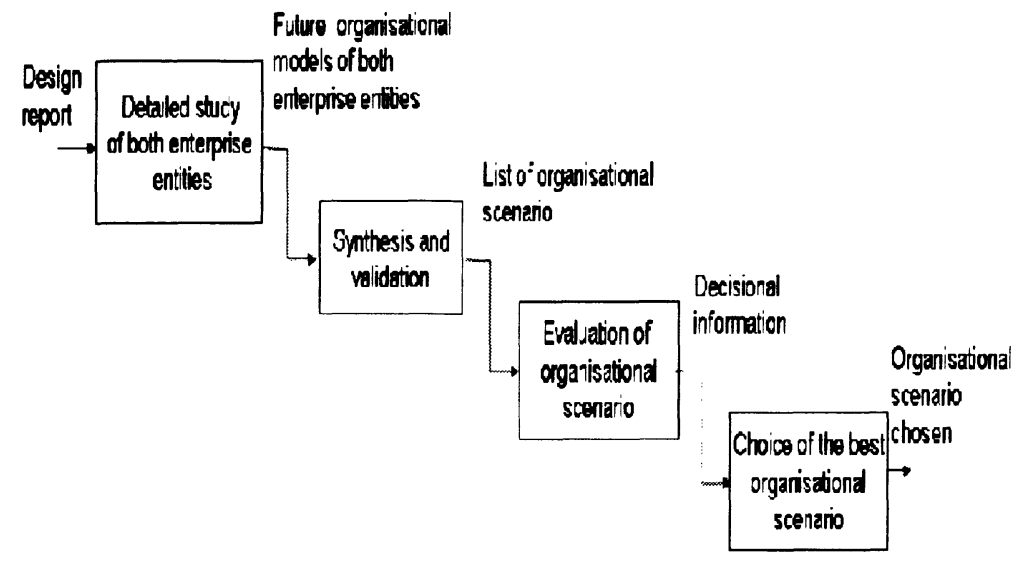

Figure 3 - Engineering activities for the preliminary engineering

Detailed study: For both enterprise entities "Organisation Network" and "Business", the detailed study describes with a sufficient level of precision the processes, inter-organisational roles, resources used, organisational relationships, rights and obligations of partners, etc. In the design phase, we apply a top-down approach with respect to the decomposition principle. The detailed study can use either a top-down or a bottom-up approach. The main engineering activities are summarised in table 3 :

Table 3 - Engineering tasks detailed study

\begin{tabular}{|c|c|}
\hline Modelling View & Engineering tasks \\
\hline Functional view & $\begin{array}{l}\text { Development of organisational solutions. by defining the macro-competencics } \\
\text { required to carry out such sub-processes and activities. } \\
\text { Development of a detailed description of resource roles } \\
\text { Definition of rights and obligations as well as performance indicators related to } \\
\text { sub-processes and activitics. } \\
\text { Detailed descriptions of federator or integrator clements related to functional, } \\
\text { logistic, cultural, semantic ... aspects } \\
\text { Design of adaptation means (reenginecring, migration of partner activitics, ctc.). }\end{array}$ \\
\hline $\begin{array}{l}\text { Organisational } \\
\text { view }\end{array}$ & $\begin{array}{l}\text { Detailed description of the resources to be used and affectation to resource roles } \\
\text { Modelling of the authority and coordination relationships among roles } \\
\text { Definition of allocation rules of partners to organisational units, used when } \\
\text { several partners can be in charge of a given unit or set of activities. } \\
\text { Detailed description of the different modelling concept attributes. }\end{array}$ \\
\hline Application view & $\begin{array}{l}\text { Description of the treatments managed by the integration system. } \\
\text { Modelling of the software applications concerned and of their relationships } \\
\text { Modelling of the information flows of synchronisation actions. } \\
\text { Definition of the information system urbanisation rules to be used for the } \\
\text { development of the future solutions. }\end{array}$ \\
\hline Knowledge view & $\begin{array}{l}\text { Construction of the future concept models } \\
\text { Construction of the future task models }\end{array}$ \\
\hline
\end{tabular}

As shown in figure 1, during the preliminary engineering the macro-competency model is detailed and the eight preliminary engineering models are built. Among them, the models of the content view constitute more detailed versions of the design models generated in the previous step, while the models of integration view are created at this stage. 
The macro-competency model presents the macro-competencies required for the full execution of the process "Production and delivery of safety devices to the international markets". The macro-competencies are linked to the organisational roles. They can be broken down into more detailed macro-competencies and, later, they can be mapped with the macro-competencies of each organisational unit.

The engineering models for the functional view are more detailed versions of the design models. Each sub-process and activity of the process in annexe 1.1 is specified through the macro-competencies required, the rights and obligation related to their execution, their performance indicators, execution time, transport time, and execution costs. Project teams also define the integration of information, logistic, and cultural aspects, and they specify the inputs and outputs of each sub-process and activity. For the data engineering model, the data classes firstly defined in design step are further specified by the description of their methods and by the enrichment of their attributes. A common semantic class is defined. The engineering models of the organisational view are also more detailed versions of the design models.

A detailed study of the integration view must be done, resulting in various models associated with the integration views. Among these models, annexe 1.2 shows the application integration engineering model underlying notably the software applications taking part in the process, the flows exchanged and the synchronisation actions realized at the level of the process. In this model, a role takes in charge one or several activities; this role is affected to a partner who uses his own enterprise applications, which requires the inter-application synchronisation mechanisms.

Evaluation and selection of organisational scenarios: These activities lead to the choice of the best functioning and organisational solutions. The "scenarios evaluation" activity specifies the information required to compare the scenarios: which descriptive parameters of the organisation network have to be considered and which evaluation criteria are to be used? The evaluation of organisational scenarios has to consider a very large number of variables and factors. In (Zaidat, 2005), we proposed a scientific approach for this evaluation based on complexity-reduction. Our proposal considers notably that the comparison among organisational scenarios can focus at first on the information system dimension.

The "selection" activity consists in integrating all evaluation criteria in an operational evaluation method, applied to choose the best organisational scenario. In our research we refereed on that point to existing decision-aid approaches. Examples of evaluating methods of information systems can be found in (Aubert et al., 2003).

\section{CONCLUSION}

This paper partially illustrates the specification of an engineering methodology for Organisation Networks. A more complete conceptual specification is provided by (Zaidat, 2006) with more details on the application and the concrete implementation in the modelling toolkit ADONIS. This research demonstrates the feasibility of a complete methodology really dedicated to O.N. engineering. However, further work remains necessary so as to make the method really operational, with the objective to provide a real decision-making environment for O.N. management. 


\section{REFERENCES}

1. Aubert B.A., Vandenbosch B. and Mignerat M., Towards the measurement of process integration. Scientific series of CIRANO (Centre Interuniversitaire de Recherche en Analyse des Organisations), 2003.

2. Chalmeta R. and Grangel R, ARDIN extension for virtual enterprise integration, Journal of Systems and Softwarc, 67(3), pp. 141-152, 2003.

3. GERAM, Generalised Enterprise Reference Architecture and Methodology. The ISO 15704 Requirements for Enterprise Reference Architccture and Methodologies, 2000.

4. GrecoPME project, under coordination of Burlat P., GRECOPME II: GRoupements d'Entreprises Coopérantes- Potentialités- Moycns-Evolutions, Final report, March 2003

5. TELEflow project, TELEflow reference architecturc, Final Report, 1996-1998.

6. Zaidat A., Spécification d'un cadre d'ingénicric pour les réscaux d'organisation, PhD thesis, ENSM.SE - Ecole nationalc supćricure des mines de Saint Eticnne, Scpt. 2005.

7. Zaidat A., Boucher $\mathrm{X}$. and Vincent $\mathrm{L}, \mathrm{A}$ framework for organisation network engincering and integration, Robotics and Computer-Integrated Manufacturing, 21, pp. 259-271, 2005

8. Zaidat A., Vincent L., Boucher X. : "A Modeling Framework For Organisation Networks », 12th IFAC Symposium INCOM'06, Saint Etienne, France, May 2006, A. Dolgui, G. Morcl, C. Percira (Eds.), Elscvicr Science, 2006, ISBN: 978-0-08-044654-7, vol. 2, pp. 577-582

9. Zwegers, A., Tölle, M. and Vesterager, J: Virtual Enterprise Reference Architecture and Methodology. Globemen book, Iris Karvonen, VTT Industrial Systems, Finland, 17-36, 2003. 


\section{ANNEX}

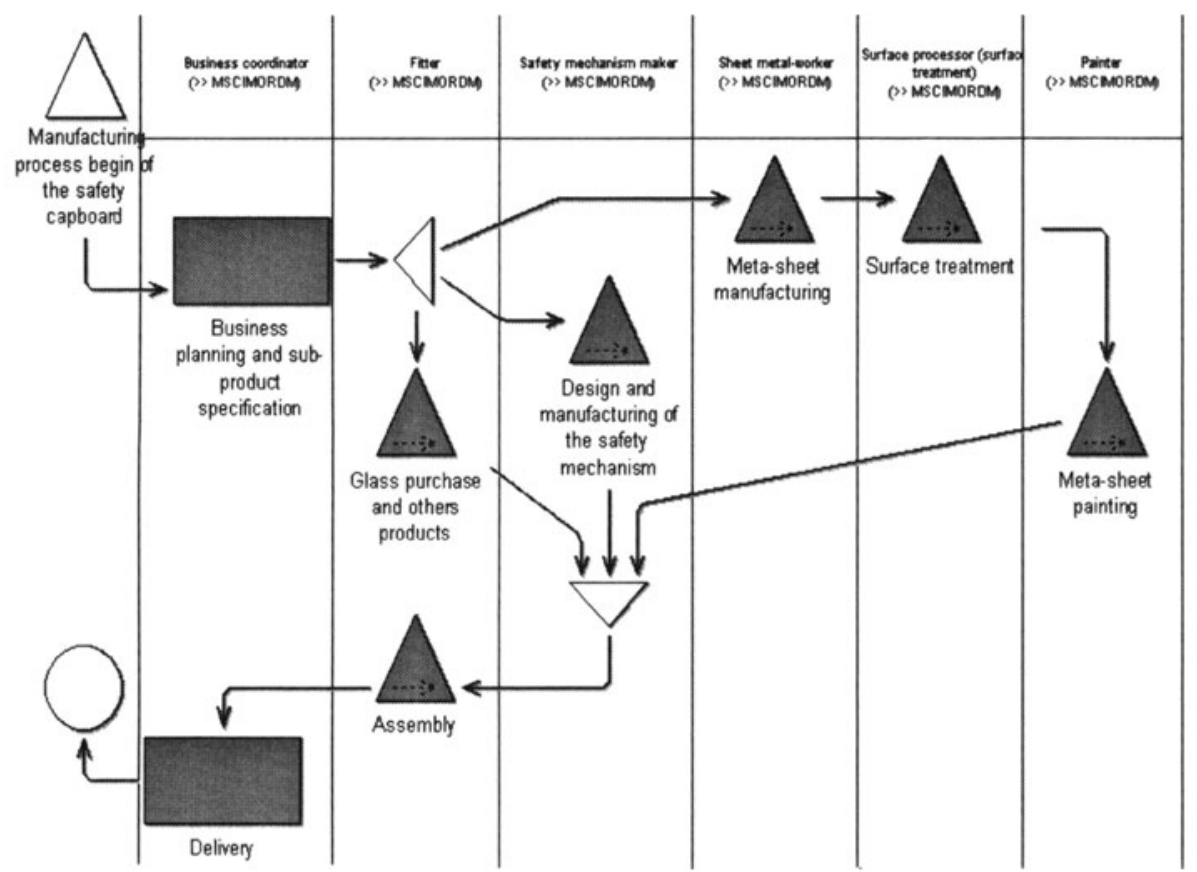

Annex 1.1 - Process design model for PDSDIM

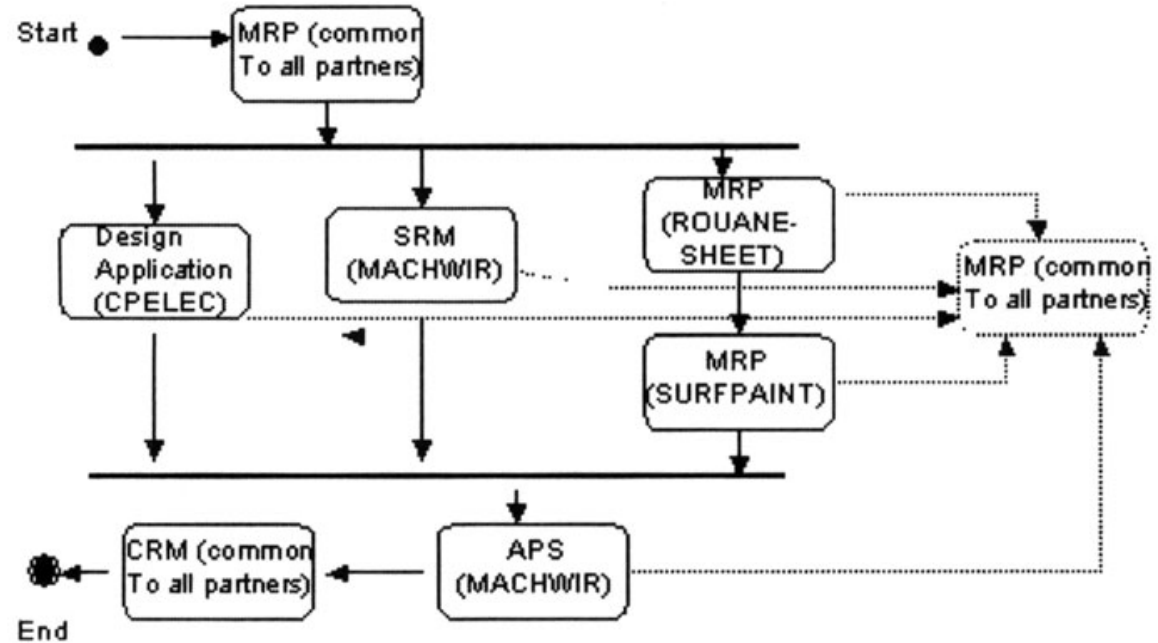

Annex 1.2 - Application integration engineering model 